\title{
CULTIVATING RESPONSIBLE DESIGN WITH THE PRODUCT IMPACT TOOL
}

\author{
Wouter EGGINK \\ Industrial Design Engineering, Faculty of Engineering Technology, University of Twente
}

\begin{abstract}
Industrial Design Engineers have a social responsibility by the very nature of their activities, bringing new products and services into the world of the user. Within the design related research chairs of our university we strive to shape this responsibility in the context of the design of Human Technology Relations. This paper will report on the experiences with teaching responsible design in the context of an Industrial Design Engineering Master's course "Create the Future". In this course student groups explore the future of a specific design domain by means of future scenario development. In the course, the potential impacts of future design interventions are actively explored by means of the Product Impact Tool. This is a framework, derived from Philosophy of Technology and User Centred Design that addresses the multitude of impact types that technologies have on humans and human behaviour. In the course, the student groups analysed and evaluated their conceptual designs with the tool in a half-day workshop. Looking at the influence of the Product Impact Tool exercise on the final design results of the course, we can conclude that the use of the Product Impact Tool is valuable for the implementation of responsible design in design education.
\end{abstract}

Keywords: Responsible design, product impact tool, scenario development, philosophy of technology, practical turn

\section{INTRODUCTION}

Industrial Design Engineers have social responsibility by the very nature of their activities; bringing new products and services into the world of the user [1]. Recently there is also raising interest in specifically addressing social issues by deliberate design interventions [2]. One can think of healthrelated issues like obesity or the raising costs of healthcare. How can we design products that encourage people to do more exercise? Or to consume less? How should a robot system that supports people with dementia behave? And what does this mean for the existing caregivers? And how should we as designers deal with unforeseen outcomes or unwanted side-effects of our design interventions?

This paper will report on the experiences with teaching responsible design in the context of an Industrial Design Engineering Master's course "Create the Future". In this course student groups explore the future of a specific design domain by means of future scenario development [3]. In the design phase, the potential impacts of the proposed future design interventions were actively explored by means of the Product Impact Tool [4]. The Product Impact Tool is a framework, derived from Philosophy of Technology and User Centred Design, that addresses the multitude of impact types that technologies have on humans and human behaviour.

The paper will describe the approach of the Product Impact Tool, the implementation in the course in a half-day workshop and the outcomes of the student's analyses. After that, it will look at the influence of the Product Impact Tool exercise on the students' design results. From there it will discuss the value of the method for the implementation of responsible design in design education.

\section{RESPONSIBLE DESIGN}

Designers can change the world we live in; therefore, they have a responsibility towards the other people that live in that world. As design is also future oriented, we can easily extend this responsibility to the future generations of people. Within the design related research chairs of our university we strive to shape this responsibility of the future engineer in the context of the design of Human Technology Relations [5]. At this time we discern three different perspectives on the implementation and consequences of this social responsibility for design theory and practice [6]; 
- Designing in a socially responsible manner by organizing the design process in a responsible way. This means that all stakeholders have their part to say in the development of new products or technologies. This strand builds on the ideas of the participatory Design Movement [7], combined with developing theories from Scenario Based Design [8].

- Designing in such a way that the responsibility of the user is addressed in or with the product. This strand is represented by the idea of Open Script Design [9]. The idea is that responsibility is shared between the designer and the user, by leaving the exact use of the product (more) open to interpretation by the user [10].

- Designing in such a way that the outcome (product or service) encompasses social responsibility. This is done by investigating or exploring the impact of products in society and social context. Important instruments in this exploration are the Product Impact Tool by Dorrestijn [4] and Mediation Theory by Verbeek [11].

Although these three perspectives are complementary, and powerful in supporting the designer in executing his profession in a responsible manner, they all have their limitations. Focus on the process of designing and incorporating input from all stakeholders gives less control over the actual outcome. Sharing the responsibility of the designer with the user in an open script design means that also the control over the outcome of the design intervention is shared, and focus on the impact of the product or service itself relies on the analysis in hindsight. On the other hand, previous research into the application of the Product Impact Tool revealed that it can also be helpful in prospective thinking, especially as more concrete concept designs are conceived [12]. Therefore we decided to use (and test) the last way of implementing responsible design within our course "Create the Future", where student groups had to develop innovative applications of lighting technology for the year 2040, based on future scenario development.

\section{CREATE THE FUTURE}

The Master's course "Create the Future" is built around using explorative context scenarios [13]. In a ten-week timeframe groups of four or five students develop a future design project. For this course we adapted the scenario technique to the aims of product design, emphasizing the structure and visualisation of the explorative scenarios [3]. The resulting method consists of six successive steps [14]. The first five steps work towards the presentation of three different future context scenarios. The three scenarios are meant to show different possible and plausible futures, based on the interpretations of the extrapolation of the most important contemporary trends and developments (Figure 1).
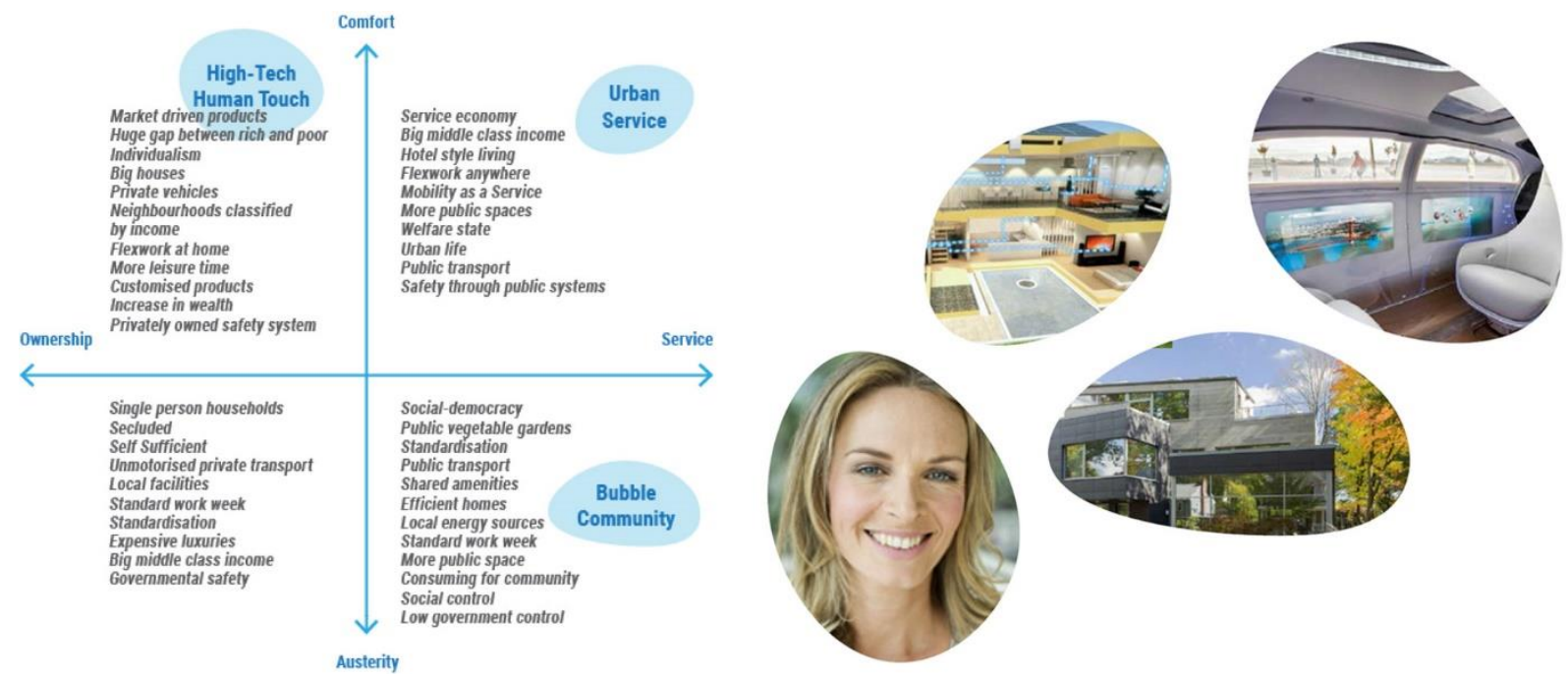

Figure 1. (left) so-called strategic space with three scenario plots in blue and (right) a visual impression of the High-Tech Human-Touch scenario by Emma Baur, Irma Harms, Mick Slots, Arnt Vollmar and Femke Wonink

Then the last step in the method is the conceptual design of a future product or service that fits within one of the developed scenarios. Because the future will always have unpredictable aspects, the focus of the course is on the consistency between the identified developments, the presented scenarios and the resulting design (see also Figure 4). 


\section{PRODUCT IMPACT TOOLS}

Dorrestijn's Product Impact Tool is a practical implementation of philosophical theories into a model intended to be helpful in the design process [15]. It offers a repertoire of exemplary types of impact of technology on humans, presented as different sides or different levels of affection. The impacts, or influences are categorized in four quadrants, named before-the-eye, to-the-hand, behind-the-back, and above-the-head (Figure 2) [16].

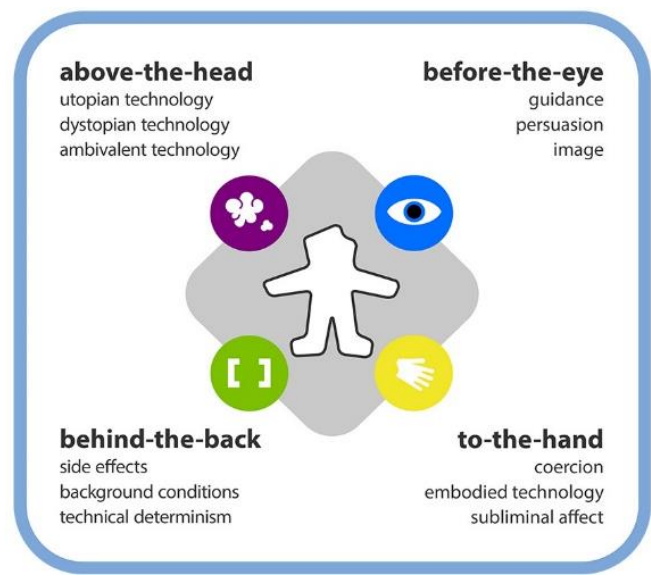

Figure 2. Product Impact Tool model with four quadrants

Before-the-eye (or cognitive) means that technology impacts the actions of users by supporting and directing the cognitive processes of decision-making. The first type of influence in this quadrant is "guidance" towards intended use, like arrows that point towards an exit. The influence on human action can also be more intrusive, which is called persuasion. To-the-hand (or physical) means that technical products shortcut cognition and directly push or guide the user's body and gestures. Although having products before-the-eye may be the most common understanding of the impact of technology, having products to-the-hand is the more basic interaction. To-the-hand is about holding handles and pushing buttons, the height and comfort of chairs and desks, or the hard safety measurements of locks and helmets. The behind-the-back (or environment) quadrant addresses influence on people in an indirect way. Here, the technical environment and accompanying infrastructure form a background that facilitates and directs human action. Think of playing music to make a cosy atmosphere in shops or the charging infrastructure that allows us to travel longer distances with electric cars. The above-the-head quadrant is the most abstract mode of interaction and looks at the relations between humans and technologies in general. What is the nature of technology? How does technology influence human freedom, privacy or independence? The philosophical views of technology vary from "utopian technology" to "dystopian technology", with "ambivalent technology" as the contemporary synthesis in the middle. Utopian technology might mean that people are convinced that prenatal screening technology will eradicate hereditary diseases, while dystopian technology thinks that the same technology will lead to inequality and discrimination [17]. Opinions in this quadrant are mostly diverse and often also contradictory. Still, these generalized visions help to understand ethical controversies and can bring the people's attitudes and concerns to the fore [16].

Main goal of using the Product Impact Tool in design is to foresee the positive and desired, however also negative and unwanted influences of a design. The four quadrants and underlying impact types should help the designer to also foresee the less-obvious consequences and side-effects of their idea.

\section{HALF-DAY WORKSHOPS}

The Product Impact Tool is only a model. To make it work for designers it therefore has to be implemented in a method or practice [18]. For the course we chose to set-up a half-day workshop in which we started with a short explanation of the theory and the model itself and after that used the physical Product Impact Tool worksheet [19] for the exercises (see also Figure 3). The session was divided in three rounds of exercises with explanation and reflection in between. In the first exercise the students had to make a round through the four quadrants of the model, trying to describe as many impacts of their own conceptual designs as possible. Either starting from the twelve listed impact-types -like 'persuasion' or 'side effects'- and trying to match them with the design or the other way around; 
imagining an impact and then trying to categorize it in the model. After reviewing the results together, the student groups had to make a second round through the model and try to imagine any secondary effects with all the impacts that they listed in the first round. In the third and final exercise the students had to identify all the undesirable and unwanted impacts and ideate possible solutions.

\section{RESULTS}

All the worksheets were collected and scanned for analysis of the workshop outcomes. At the end of the course all designs and design reports were analysed for the possible impact of the workshop on the final design results. We will start with describing the workshop outcomes. In the first round the student groups each filled-in a Product Impact Tool worksheet (Figure 3). All student groups managed to fill the four quadrants with typical impacts. The total number of different impacts identified ranged from 7 to a remarkable 24. The average amount of impacts mentioned was 16 , which means that most of the groups were able to identify on average more than one impact per listed influence in the tool.

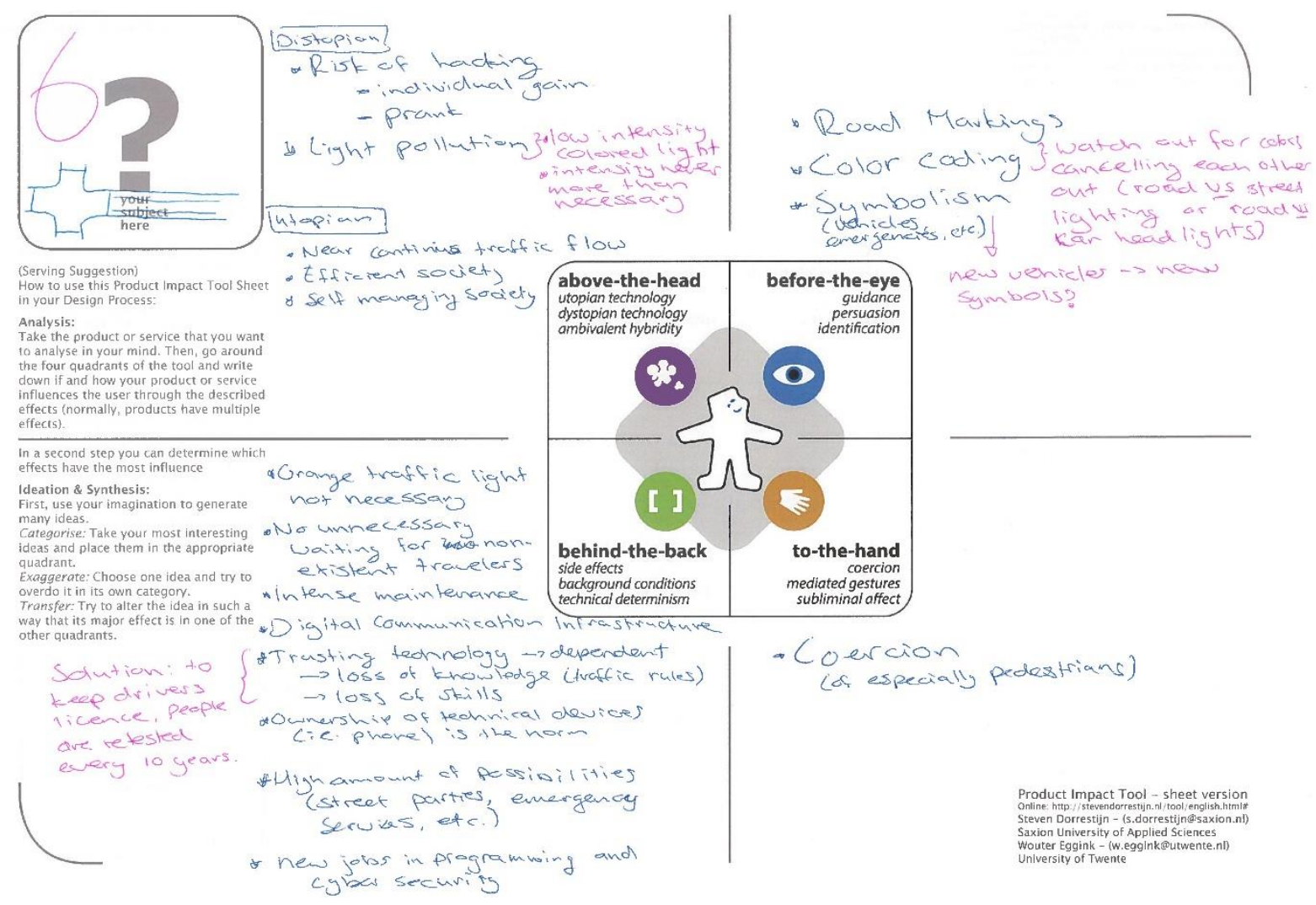

Figure 3. Example of a filled-in Product Impact Tool worksheet after the session. The unwanted impacts are accompanied by a possible solution in magenta coloured text (by Emma Baur, Irma Harms, Mick Slots, Arnt Vollmar and Femke Wonink)

In the second round, seven out of nine groups listed the unwanted (side) effects clearly in the Product Impact Tool sheet. With two student groups it was not clear which of the mentioned impacts was rendered to be unwanted. The number of unwanted effects that were explicitly mentioned ranged from 3 to 8 , with most groups listing three effects. All seven student groups that mentioned the unwanted effects also described possible solutions for them (see also Figure 3). Often mentioned were privacy issues, cyber-safety and possible inequality. However, also less obvious impacts were found. For instance, in the analysis of the concept called "Medi-Mirror", a smart device that would give medical diagnosis and support through looking in a mirror with augmented reality features, the students mention the problem of over-dependency. The first unwanted effect is then "people rely exclusively on mirror and miss underlying medical conditions". The mentioned solution: "Mirror-maintenance: to ensure mirror continue to perform a physical meeting with a doctor must be completed". The second unwanted effect is: "people become obsessive by looking in mirror (do not want to go on holiday)". The mentioned solution is to provide a downsized mobile version of the functionality: "App for temporary use will allow for limited check-up". 
For assessing the influence of the Product Impact Tool session on the end-results of the course the descriptions of the final conceptual designs in the group reports were compared with the listed unwanted effects in the worksheets. The effect of the workshop was considered positive when the problematic impacts were at least partially addressed in the design. From the seven groups that explicitly listed the unwanted impacts six groups implemented at least one of the ideated solutions in their design concept and from a total of 31 unwanted impacts, 22 were noticeably addressed in the final design. An example of such an implementation is visible in the design concept of a lighting system for mobility safety (Figure 4). This student group addressed two of the listed unwanted impacts which were "light pollution", and "trusting technology" which would lead to dependency and a loss of knowledge and skills (see Figure $3)$.
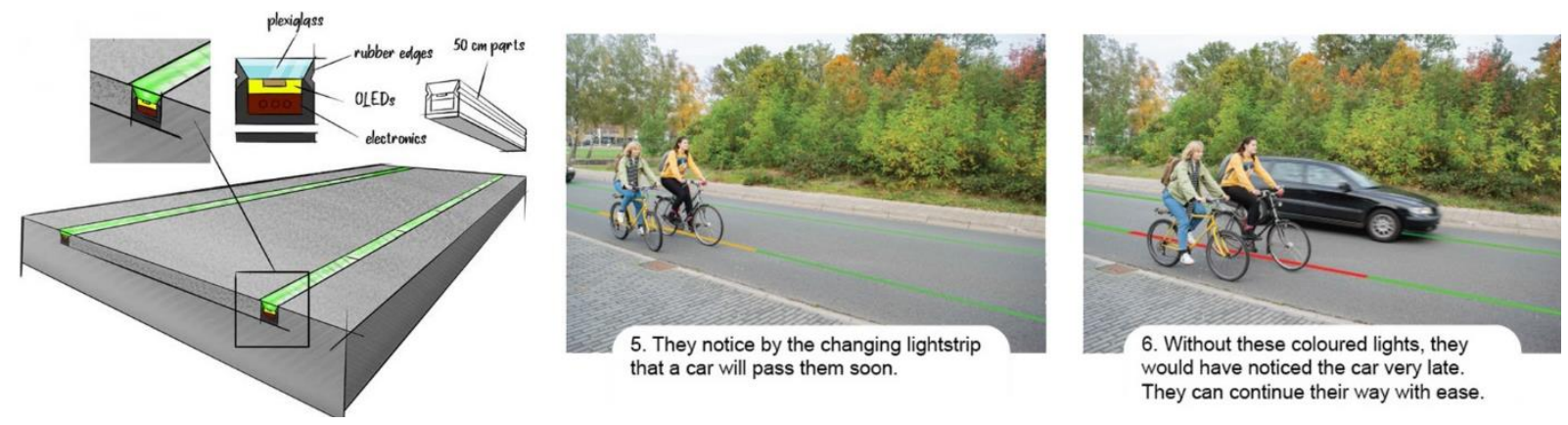

Figure 4. Impression of design concept by Emma Baur, Irma Harms, Mick Slots, Arnt Vollmar and Femke Wonink. A light system is incorporated in the streets to enhance the safety of vulnerable traffic users (cyclists and pedestrians) when more and more motorized vehicles will be driving autonomous

The first issue was addressed by using low intensity coloured lighting in the form of strips instead of lighting up the whole road. For crossroads, where more guidance (and thus more light) would be needed the system were to be programmed to use no more light intensity than necessary (less at night, more during the day). The possible over-dependency on the technology, potentially leading to a loss of skills was solved by implementing accompanying regulations: "to oblige citizens to take drivers exam every 5-10 years in order to keep their driving license and children should receive traffic education."

\section{DIscussion}

When looking at the results one can say that the usability of the tool for the evaluation of future design concepts was high. Every student group was able to complete the worksheets with impacts. Evaluating the efficiency of the tool is already more complicated as it is from the results of this course and workshop not possible to know whether the impacts that were found are purely due to the use of the tool. Would the student groups also have paid attention to things like privacy regulation, hacking of electronic systems and possible exclusion of certain societal groups without the workshop and use of the tool? That is hard to say, however some examples of less obvious or secondary impact types like the example of over-dependency and reduction of knowledge and skills make us believe in the added value. At the same time, it was clear to see the direct influence of the workshop results in the final design concepts in the reports, because a large share of the unwanted impacts was addressed. Although we must acknowledge that this influence had to be assessed indirectly, as only one student group mentioned the specific influence of the tool in their report. Again, it is hard to say whether these issues would not have been addressed without the tool. On a more fundamental level one can also argue whether the use of the tool indeed led to more 'responsible' designs. Is the systematic reflection on impacts of technology effective? We think that normally designers are inclined to think more about the desirable and positive effects of their interventions and often neglect unwanted impacts or are even unaware of secondary and negative side-effects. The systematic reflection on all types of impacts will bring more balance to the practice. It would in this respect be interesting to have some standardized test measuring the 'responsibility' or 'the inclination towards responsible behaviour' of the students before and after the course. However, we have not found that yet. Is the systematic reflection sufficient then? We have not said that in the first place, because it will always be just one of the three strands in the shaping of a responsible design practice. From the limited experiences of the workshop however, we still believe that the approach contributes to more attention to social effects and societal impacts, and to some counterweight to the 
often rosy worldview of the students regarding the benefits of technology in general and their own designs in particular.

\section{CONCLUSIONS}

The use of the Product Impact Tool within the master course Create the Future led the student groups to address unwanted effects in their designs. Although it is difficult to contribute the design improvements entirely to the use of the tool, we argue that the systematic reflection on the impacts of their designs can raise the awareness with the students of their responsibility towards the world in which they are designing. We therefore conclude that the use of the Product Impact Tool is valuable for the implementation of responsible design in design education.

\section{REFERENCES}

[1] Papanek, V., The Green Imperative. 1995, London: Thames and Hudson.

[2] Tromp, N., P. Hekkert, and P.-P. Verbeek, Design for Socially Responsible Behaviour: A Classification of Influence Based on Intended User Experience. Design Issues, 2011. 27(3): pp. 3-19.

[3] Eggink, W., A. Reinders, and B. van der Meulen, A practical approach to product design for future worlds using scenario-development. In: Proceedings of the 11th Engineering and Product Design Education Conference. 2009. Brighton: Institution of Engineering Designers.

[4] Dorrestijn, S., The Product Impact Tool: the Case of the Dutch Public Transport Chip Card., In: Design for Behaviour Change: Theories and practices of designing for change., K. Niedderer, S. Clune, and G. Ludden (Eds.). 2017, Routledge: Abingdon \& New York. pp. 26-39.

[5] Eggink, W., Where's My Robot? Integrating Human Technology Relations in the Design Curriculum. In: Proceedings of the International Conference on Engineering and Product Design Education; Human Technology Relations. 2014. Enschede: The Design Society. pp. 87-92.

[6] Eggink, W., et al., Setting the stage for Responsible Design. In: Proceedings of the biannual Design Research Society conference (DRS) Synergy. In Print. Brisbane (Australia).

[7] Garde, J., Everyone has a part to play: Games and Participatory Design in Healthcare, $\mathrm{PhD}$ in Industrial Design Engineering, 2013, University of Twente, Enschede.

[8] Bijl-Brouwer, M.v.d. and M. van der Voort, Parcipatory Scenario Generation. Design Principles \& Practices, An International Journal, 2009. 3(1): pp. 269-288.

[9] Stam, L. and W. Eggink, How to Interest People for the Hare instead of the Chase. In: Proceedings of the biannual Design Research Society conference (DRS); Design's Big Debates. 2014. Umeå.

[10] Stam, L., Social Engagement in Design: a new perspective, Ma in Industrial Design Engineering, 2015, University of Twente, Enschede.

[11] Verbeek, P.-P., Moralizing Technology. 2011, Chicago: University of Chicago Press.

[12] Raub, T., S. Dorrestijn, and W. Eggink, Using the Product Impact Tool for Prospective Thinking. In: Proceedings of the biannual Design Research Society conference (DRS) Catalyst. 2018. Limerick (Ireland). pp. 253-268.

[13] Fahey, L. and R.M. Randall, Learning from the Future, Competitive Foresight Scenarios Advantage Through Scenario Planning. 1997, New York: John Wiley \& Sons Inc.

[14] Eggink, W. and A. Albert de la Bruheze, Design Storytelling with Future Scenario Development; envisioning "the museum". In: Proceedings of the Summer Cumulus Conference. 2015. Milan: McGraw-Hill. pp. 245-256.

[15] Eggink, W. and S. Dorrestijn, Philosophy of Human Technology Relations in Design: The Practical Turn. In: Proceedings of the Philosophy of Human Technology Relations Conference (pHTR). 2018. DesignLab, Enschede (the Netherlands): University of Twente.

[16] Dorrestijn, S. and W. Eggink, Product Impact Tool Workshop; mastering affect and effect in human-product relations. In: Proceedings of the International Conference on Design \& Emotion; Colors of Care. 2014. Bogotá: Ediciones Uniandes. pp. 467-469.

[17] Verbeek, P.-P., De grens van de mens. 2011, Rotterdam: Lemniscaat.

[18] Belle, J.v., S. Dorrestijn, and W. Eggink, Design for People \& Society: Turning the Product Impact Tool into a Design Tool. In: Proceedings of the Philosophy of Human Technology Relations Conference (pHTR). 2018, Enschede (the Netherlands): University of Twente.

[19] Dorrestijn, S. and W. Eggink. Product Impact Tool worksheet. 2015 [accessed 2020, 3 March]; Available from: https://productimpacttool.org/wp-content/uploads/2019/08/190802_Product ImpactTool_Worksheet_NL-EN.pdf 